\title{
Abstracts
}

\section{The Process of Grieving}

Mary Jean Etten

Tony Walter. 1996. A new model of grief: bereavement and biography, Mortality, I (I), 7-25.

Over the last century, the most favoured model of grieving has envisioned the gradual detachment from the person who died, through the processing of the feelings and emotions prompted by the loss, and through reconciliation to life without that individual. The research and writings of leading thanatologists and researchers, as cited in this article, all support this model of resolving grief. They observe that the bereaved person experiences over time feelings, emotions and behaviours such as sadness, fear, guilt, depression, anger and acceptance. Those allow the griever to separate from the loved one and to construct a continuing life without them.

Tony Walter challenges this widely accepted prescription with a new model, based upon personal experience of the deaths of his father and a personal friend, and illuminated through the analysis of classic texts and the writings of leading researchers. The major theme identified by the author depicts the emotional processing of loss and the gradual detachment from the loved one as the 'classic' approach. His minor themes describe the survivor repeatedly experiencing a sense of the presence of the dead person and engaging in recurring conversations about the individual with family and friends.

When the author attended the funeral of his father, the Zimbabwean eulogist evoked the Shona tradition of living life in the ancestors' presence by advocating that the spirit of the deceased be kept alive as a family member and as part of the village society. To seek relational association over time with a dead person has typically been viewed by grief counsellors as an illusion or no more than a temporary experience prior to the final detachment from the individual. In the Shona tradition, burial rites acknowledge the end of the physical body but then welcome the return of the deceased as an ancestor. The eulogist's message comforted the author, who welcomed the recommendation that his father's spirit be kept alive and that they continue to talk about him. 
Support for the minor theme is presented in substantial research which indicates that the conventional model of grieving does not describe the grieving experience of all subjects. Some parents whose child died years ago refer to the child as still alive. When asked how many children they had, the number they gave included the one who had died. Respondents also believed that once a bereaved parent, always a bereaved parent. Other research on young widows also found that the traditional model of grieving was not to their liking. Rather than detaching themselves from their dead husbands, they gradually began to enjoy and treasure memories of them. Older widows too defied the traditional model by longing to be reunited with their dead husbands, and less often wished to reinvest themselves in another person. This is understandable considering the length of their marriage, their age and the scarcity of new marriage partners. Both the bereaved parents and the widows formed support groups without professional leadership, since the latter tended to pathologize their response patterns to grief. In the lay-led groups the participants support one another for varying lengths of time, often years, by sharing the memories of the dead person.

Various cited works support other approaches to grief resolution. Wortman and Silver (1 989 ) identify three common patterns of grieving, and Stroebe (1992) believes there is not just one 'normal' response pattern to grief, but multiple patterns, depending upon the individual who is grieving and the circumstances. Stroebe and Schut (1995) describe an oscillation between facing and avoiding grief as a healthy approach. In the first edition of the Grief Counselling and Grief Therapy, Worden (1983) gave his fourth task of mourning as 'withdrawing emotional energy from the deceased and reinvesting in another relationship', but this was changed in the second edition to, 'not to help the bereaved give up their relationship with the decreased, but to ... find an appropriate place for the dead in their emotional lives' (I99I, I6). It is recommended that counsellors be open to diverse patterns of individual grieving supported by cross-cultural data rather than adhere to the normal versus pathological grieving model. Forming new relationships is not seen as necessary for healthy functioning following a death, and how one adapts is an individual matter. The Jewish custom of Shiva allows for the exchange of memories of the deceased over seven days and the fahrzeit, an annual remembrance ceremony, encourages the family to speak about the loved one to construct memories that endure.

A detailed account of grieving for a former girlfriend, Corina, then follows. In arranging for and participating in her memorial service, the 
author spoke with over 200 people who knew her. Sharing their experiences of Corina with each other helped to develop in their minds who she really was, clarified their thoughts of her, helped them deal with unfinished business, healed their wounds and allowed them to look to the future.

The author cites Victor Marshall's (1986) work which describes the process of reminiscence, going over one's past life in preparation for death and to enjoy life in the future. Common among people in advanced old age, this experience is called 'writing the last chapter'. Contrarily, the author describes 'writing the last chapter' as the sharing and reconstructing of a loved one's life by friends and family in a eulogy, an obituary, and inter-personal interaction following his or her death. The lessened attachment to religion, tradition and ritual may lead individuals in modern society to reconstruct the deceased person's identity, producing an even greater need for sharing with others who the deceased really was, their former relationship, and significant circumstances surrounding the death to be able to deal with the loss.

Funerals, memorials, services, letters of condolence and the English 'funeral tea' all allow grievers to share their thoughts and feelings about the deceased. But reduced opportunities to talk with others about the death of loved ones seems to be more prevalent, for the following reasons: (I) following sudden deaths little is known concerning how the person died; (2) since family and friends grieve differently and for disparate durations, sharing with each other is often impossible; (3) religious and other beliefs and practices vary from one generation to another, often producing contrasts in understanding and appreciation of the loss; (4) family members rarely know friends from work, making it impossible to share thoughts of the deceased with one another; and (5) geographical mobility separates families, neighbours often do not know neighbours, and older people are gradually stripped of their peers and with their remaining friends and confidants increasingly experience sensory losses and social isolation. All these circumstances tend to inhibit the social interaction whereby the deceased person's role and meaning as an ancestor are established.

The role of counselling and self-help groups is then discussed. Bereaved individuals who have no one to speak with and who knew the deceased person often choose counselling or self-help groups. While the group members cannot share in the reconstruction of what the deceased person was like, how the person died, and what took place, they can share similar feelings and experiences. While accepting one's feelings and crying may cause the griever to feel better, the author 
challenges counsellors to produce research findings which support alternative models to the traditional representation of grief.

In conclusion, the author summarizes the main elements of the article: (I) people who are bereaved wish to speak with others who knew the deceased person; (2) bereavement counselling or self-help groups encourage grievers to express their feelings and, while this expression may be helpful, it could be seen as a poor second best; (3) grief's purpose is to find a place in one's life for the deceased person, by developing an accurate image of the person, which is approached through sharing information with others who knew them; (4) finding others to share knowledge of the deceased may be difficult in such a mobile society in which people live long lives; (5) an individual's existence is validated and made sense of through continued conversation and reflection about the person. The author agrees that some individuals may work through their feelings and gradually detach themselves from the dead person; others, however, may speak to one another about the deceased to create a special place for the person in their lives.

If new research does find that people grieve as the author suggests, funerals should focus on who the person was, and a biography of the person should be shared to encourage exchanges for months to come. This would create an enduring place for the deceased person in others' lives. This model seems to fit the grief response of the British more accurately than the model encouraging the expression of feelings, since few are comfortable with emoting at funerals. Lastly, it is recommended that counsellors encourage the bereaved to speak with others who knew the deceased and that they should assist contacts by telephone, letter and visit. Furthermore, the bereaved should be supported to retain the deceased in their mind and lives. This assurance liberates them and helps them to move on in their lives.

\section{Comment}

Reading this article and several cited in the references offers a refreshing new look at the process of grieving. It challenges the traditional ascribed model and encourages consideration of other models. With the many recent advances in the social and behavioural sciences, the time seems ripe for greater openness to other models of grieving. And with the explosion of interactions among peoples all over the world, it behoves us to learn about and acknowledge the variety of grieving patterns across many cultures and religions. New studies should also examine the patterns of coping with dying which, in the 
past, have for the most part paralleled the model for grieving. Hawkins (I99 I) and Doka (I995) both assert the uniqueness of each individual's dying and invite more openness to varied responses.

The model of grieving advanced by the author offers new challenges and creative approaches to those responsible for funeral arrangements and for religious groups. Our societies should offer greater freedom for grievers to choose rituals they value and to connect more effectively with others in sharing memories of the deceased. Even the computer might play a useful if impersonal role in hclping to create meaningful memories of the deceased. Lastly, the validation of other models of grieving could greatly modify our view of pathological responses. The assessment instruments now used to identify pathological grieving might need to be rewritten, and approaches to counsellors might need to revise their approach.

\section{References}

Doka, K. 1995. Coping with life-threatening illness: a task model. Omega 32, I I I-I 2 I. Hunasker Hawkins, A. I99I. Constructing death: three pathographies about dying. Omega, 22, 301-317.

Marshall, V. W. I986. A sociological perspective no aging and dying. In: V. W. Marshall (ed.), Later Life: The Social Psychology of Aging. Sage, London.

Stroebe, M. I 992 . Coping with bereavement: a review of the grief work hypothesis. Omega 26, 19-42.

Stroebe, W. and Schut, H. 1995. The Dual Process of Coping with Loss. Paper presented at the International Work Group on Death, Dying and Bereavement, Oxford.

Wortman, C. B. and Silver, R. G. 1989 . The myths of coping with loss. Fournal of Consulting and Clinical Psychology 57, 349-357.

Worden, J. W. 1983. Grief Counselling and Grief Therapy. Routledge, London. Second edition, I991.

\section{European Policy Issues}

\section{Tony Maltby}

J. Večerník. Incomes in central Europe: distributions, patterns and perceptions, Journal of European Social Policy, 6, 2 (I996), Iо I-1 22.

The first abstracted article offers comparative data on earnings and household incomes in what are sometimes referred to as the "Visegrad Four' countries (Hungary, Poland, Slovakia and the Czech Republic). All face similar problems in the provision of social welfare, but systematic and reliable comparative statistical information on earnings and household incomes among them is difficult to come by. This important article analyses recent trends since 1989 in the distribution of earnings and household incomes across and within the four countries. The paper draws from several sources, notably Social Stratification in 